\title{
Estatuas antiguas en contextos islámicos: el discurso de DAESH - la respuesta a la Historia ${ }^{1}$
}

\author{
Ancient Statues in Islamic Context: \\ DAESH's Discourse - The Response to History
}

Jorge Elices Ocón*

\begin{abstract}
Resumen
El presente artículo analiza el discurso elaborado por DAESH, centrado en la antigüedad. Más allá de su carácter radical y destructivo, el discurso esconde una mayor complejidad de lo esperado, puesto que camufla sus verdaderos argumentos bajo una falsa apariencia de conflicto religioso, participa de debates actuales en torno a la narrativa histórica que se construye a partir de la arqueología, las piezas y los museos, se apropia de ideas del discurso occidental y colonialista, tergiversa y reinventa el pasado y oculta no solo la realidad de un tráfico de antigüedades, sino que también busca destruir la existencia de otras percepciones de las estatuas, apegadas a la memoria y las tradiciones de las comunidades locales, que hacen de las estatuas mucho más que meros ídolos de la Ŷāhiliyya, la época anterior a Muhammad y el islam.

Palabras claves: estatuas; ídolos; DAESH; colonialismo; arqueología.
\end{abstract}

\begin{abstract}
This article analyzes the discourse developed by DAESH, focused on antiquity. Beyond its radical and destructive nature, the discourse hides greater complexity than expected, since it disguises its true arguments under the false appearance of a religious conflict, participates in current debates regarding the historical narrative built around archeology, pieces and museums, appropriates of ideas taken from the western and colonialist discourse, misrepresents and reinvents the past, and hides not only the reality of an antiquities trade, but also aims to destroy the existence of other perceptions linked to statues, attached to the memory and traditions of local communities, who saw in these statues much more than mere idols of the $\hat{Y}$ āhiliyya, the time before Muhammad and Islam.

Keywords: statues; idols; DAESH; colonialism; archaeology.
\end{abstract}

\footnotetext{
* Universidade Federal de São Paulo (Unifesp), Guarulhos, SP, Brasil. jorge.elices.ocon@gmail.com $<$ https://orcid.org/0000-0002-4794-7934>
} 
El nuevo museo Louvre Abu Dhabi abrió sus puertas en Noviembre de 2017 tras una larga espera de casi 10 años. Su intención es la de celebrar la creatividad universal de la humanidad, desde la prehistoria hasta el presente, invitando a su público a ver la sociedad humana bajo una nueva luz. El museo es fruto de la colaboración entre la ciudad de Abu Dhabi y el gobierno francés, y ha permitido a este enclave enigmático del Golfo Pérsico alcanzar nuevas cifras récord, pues se trata del mayor museo en la Península Arábiga y uno de los más relevantes, por su magnitud y presupuesto, del Próximo Oriente. Además, durante 30 años, y gracias a la firma de un acuerdo, el museo de Abu Dhabi estará asociado al Louvre francés, haciendo gala del mismo nombre y acogiendo igualmente piezas y exposiciones procedentes de la famosa cámara de maravillas de París (www.louvreabudhabi.ae; Seisdedos, 2019).

Entre las piezas seleccionadas para la inauguración del museo se contaban diversas antigüedades, entre ellas estatuas y bustos mesopotámicos y greco-romanos, figuras en piedra o mármol blanco, semidesnudas en algunos casos, representando a los gobernantes y dioses del pasado. Las fotografías tomadas durante el evento muestran al público local, oriental, árabe y musulmán, contemplando una serie de obras que, en principio, pensaríamos que resultan más aceptables y familiares al público occidental (Figura 1).

Figura 1 - Visitantes del Louvre Abu Dhabi durante la inauguración del museo el 11 de noviembre de 2017. Foto de Karim Sahib/AFP. Tomada de Vicente, 2019.

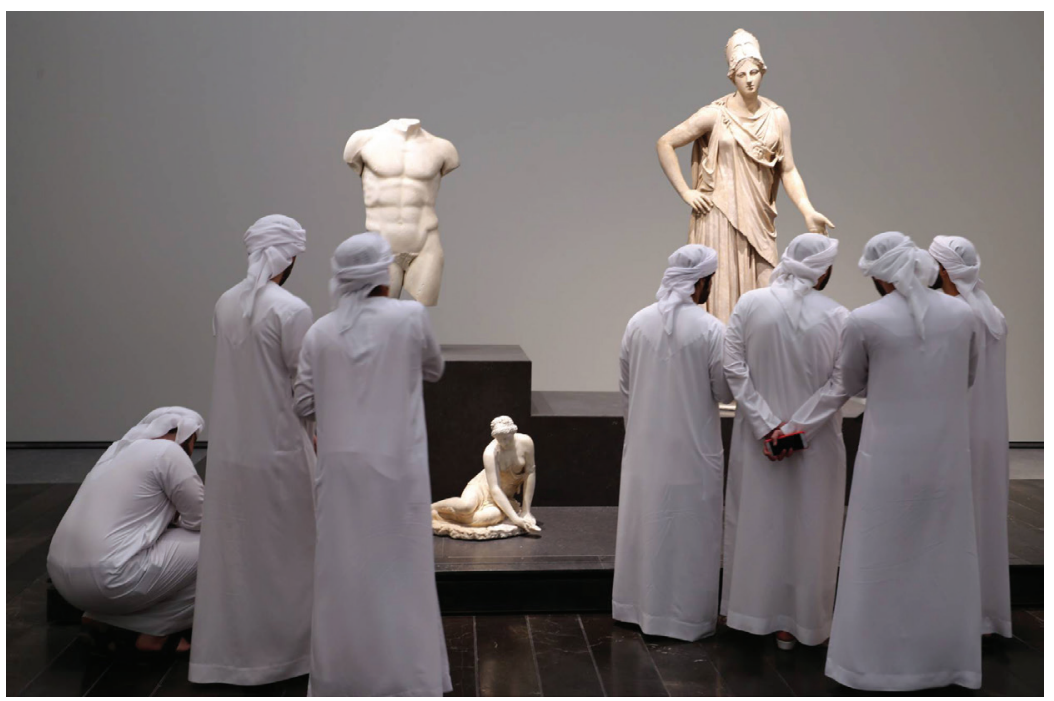


Con todo ello es inevitable plantearse una serie de cuestiones actuales, debates en torno a aspectos políticos y académicos, con una enorme repercusión internacional, como pueden ser la tolerancia o prohibición con respecto a la imagen figurada en el mundo islámico; el retorno a la región, de manera temporal, de algunas piezas que habían sido creadas originariamente en Oriente y Mesopotamia; la comercialización o internacionalización de una institución como el Louvre; el papel de las estatuas y antigüedades en la actualidad; y el respeto a los derechos humanos o la connivencia con su violación en países como Emiratos Árabes Unidos (Vicente, 2019; Las Autoridades..., 2017).

Apenas dos años antes, no muy lejos de allí, en Mosul (Iraq), los terroristas de $\mathrm{DAESH}^{2}$ destruían las piezas del museo arqueológico de la ciudad, difundiendo posteriormente, el 6 de marzo de 2015, un vídeo en las redes sociales, en el que mostraban la destrucción que habían llevado a cabo, sin ningún tipo de misericordia (Erasing..., 2015). El video causó estupor y consternación en Occidente. Los principales medios de comunicación se hicieron eco del acto cometido que recordaba, de forma inevitable, destrucciones anteriores como la llevada a cabo por los Talibanes en 2001, que significó que los famosos Budas de Bamiyán fueran dinamitados (Flood, 2002, p. 655; Elias, 2007, p. 12-29; Morgan, 2012). El shock sirvió para grabar a fuego en la comunidad internacional la idea de que el islam rechaza cualquier evidencia de un pasado ajeno al suyo propio, y en concreto, no tolera la representación figurada (Figura 2).

Figura 2 - Terroristas de DAESH destruyendo varias estatuas en el Museo arqueológico de Mosul (Irak). Imagen del video.

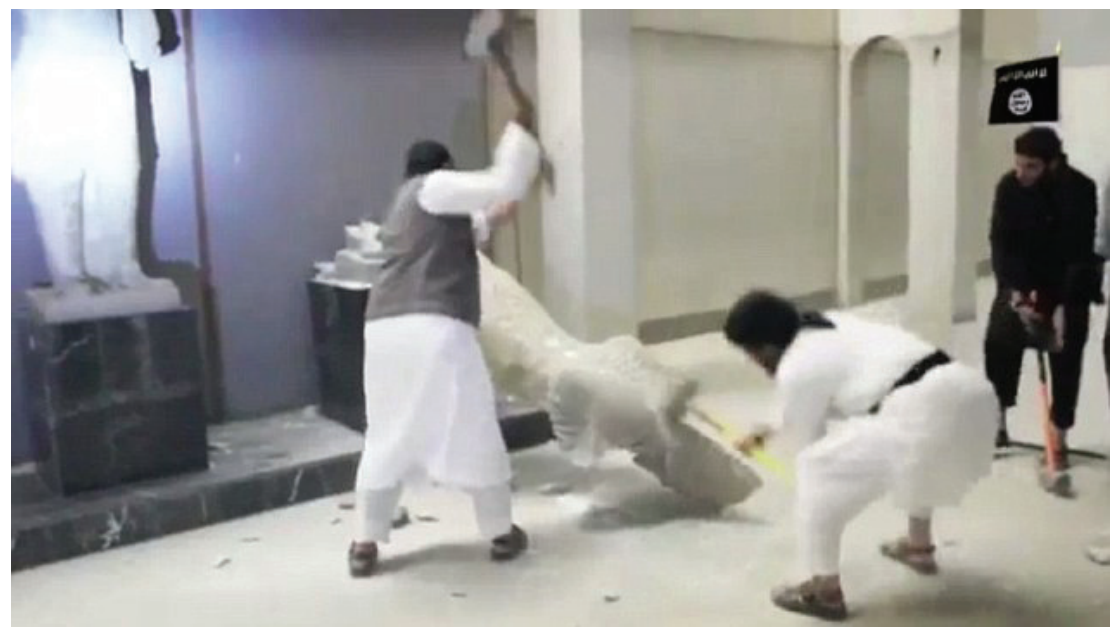


El contraste entre estos dos momentos pone en evidencia que la imagen del pasado y en concreto las antigüedades y estatuas, ocupan un lugar central en las narrativas actuales sobre el pasado y el presente, tanto en Oriente como en Occidente, con las cuales construimos nuestra propia identidad histórica como sujetos y comunidad. Diversos estudios han profundizado en aspectos tan relevantes como el uso y abuso del pasado y el nacimiento de la arqueología en el contexto del colonialismo del siglo XIX (Marchand, 1996; Schnapp, 1998; Díaz-Andreu, 2007; Goode, 2009; Bahrani; Çelik; Eldem, 2011); los actos iconoclastas y destructivos que han tenido lugar a lo largo de la historia, muchos de ellos llevados a cabo en nombre de la religión (Gamboni, 1997; Kolrud; Prusac, 2014; Kristensen; Stirling, 2016); el origen de los museos como instituciones al servicio de una determinada narrativa histórica (Shaw, 2003, p. 38-39; Çelik, 2016); el anticuariado europeo y nuevas formas de percepción de las antigüedades no eurocéntricas (Hamilakis, 2011; Schnapp, 2007; Schnapp, 2008; Schnapp et al., 2013; Anderson, 2015; Anderson; Rojas, 2017) o el tráfico de antigüedades en Oriente Próximo y, concretamente, el orquestado por DAESH y otros grupos gubernamentales o rebeldes al régimen durante la guerra en Siria e Iraq (Brodie; Sabrine, 2018).

Lo que todavía no se ha puesto de manifiesto es el trasfondo desde el cuál se erige el discurso de DAESH y sus características en relación a la antigüedad. Lejos de ofrecer una contradicción total, las imágenes de Abu Dhabi y Mosul coinciden en varios aspectos, como puede ser el gusto por la escenografía y el espectáculo, evidente en las grandilocuentes construcciones llevadas a cabo en Abu Dhabi y en el espectáculo del horror al que recurre DAESH, ambas consiguiendo gran eco en los medios de comunicación internacional (Harmanşhah, 2015; Smith et al., 2016; Bearden, 2016), o el oscuro origen de algunas de las piezas pertenecientes a las colecciones públicas y privadas a lo largo de todo el mundo, de tal manera que puede darse la paradoja que, parte de estos museos occidentales y de los jeques árabes del Golfo Pérsico que financian proyectos museísticos similares y visitaron las salas del museo Louvre Abu Dhabi, convivan y participen de este mercado ilegal al amparo de la ausencia de leyes internacionales explícitas (Leroy, 2014; Taub, 2015).

No obstante, me interesa destacar aquí un aspecto común muy concreto: ambas imágenes ahondan en la desvinculación de la población local con el pasado y las antigüedades propias de la región. La imagen del Louvre Abu Dhabi profundiza en la globalización de una única lectura del pasado y sus restos materiales, coincidente con la visión occidental o europea, en la que estas piezas son consideradas únicamente como obras con un valor histórico, 
artístico y científico. La imagen del video de DAESH ofrece una lectura mucho más radical y esencialmente destructiva: las antigüedades, particularmente las estatuas y esculturas antropomorfas y zoomorfas, son ídolos paganos, igualmente ajenos a la tradición y civilización islámica, que deben ser destruidos.

En ambos casos, la población local queda al margen y las antigüedades no forman parte de la narrativa sobre la historia, memoria e identidad local. Ante todo son piezas descubiertas por arqueólogos europeos y conservadas en los museos occidentales, expuestas temporalmente en el Louvre Abu Dhabi. Es mi impresión que este proceso de alienación, que se retrotrae a época colonial, como veremos, conforma uno de los pilares sobre los que se ha construido el discurso de los terroristas de DAESH.

Otro pilar que fundamenta el discurso de DAESH es una radical interpretación de la ortodoxia islámica. Esta afecta no solo a la tolerancia con respecto a la imagen figurada, según la lectura sesgada del Corán y la tradición islámica que ofrecen los terroristas, sino también repercute, y esto resulta fundamental, en la propia narrativa sobre el pasado y la memoria de las comunidades locales, ocultando y reescribiendo una historia caracterizada fundamentalmente por su heterogeneidad y diversidad, evidente en las múltiples religiones, iconografías y tradiciones culturales en Oriente, que, sin embargo, DAESH intenta destruir y reescribir, para figurar como único protagonista de una historia simplificada e irremediablemente homogénea y unilateral (Bahrani, 2015).

Mi intención en este artículo es analizar el discurso de DAESH, indicar su origen y principales argumentos en relación a la antigüedad, evidenciando que, lejos de ser solo un discurso radical y meramente destructivo, como es evidente, esconde una enorme complejidad y abarca diversos procesos de reescritura del pasado. En concreto, me interesa señalar como este discurso silencia una determinada percepción de las antigüedades y de las estatuas, habitual durante época medieval y moderna, sustituyéndola por una lectura del pasado en términos políticos y religiosos, erigida como respuesta a la Historia.

\section{El DisCuRSo DE DAESH: MÁs ALLÁ DE LOS ARGUMENTOS RELIGIOSOS}

Para ver cuáles son los argumentos esgrimidos por DAESH podemos analizar uno de los vídeos publicados por los terroristas en el que se recoge la destrucción sistemática de las piezas del museo de Mosul. En él hay dos momentos destacados: primero, la presentación de las piezas que van a ser 
destruidas y la exposición de los argumentos para ello, y segundo, su destrucción. En esta primera parte un miembro de DAESH toma la palabra:

Musulmanes, estas ruinas detrás de mí son ídolos y estatuas que adoraban los pueblos antiguos. Ellos no adoraban a Allāh. Los Asirios, Acadios y otros pueblos tenían dioses para la guerra, la agricultura o la lluvia y les ofrecían sacrificios [...] Cuando Abraham fue a La Meca destruyó los ídolos, y cuando Muḥammad fue a La Meca destruyó los ídolos que la gente estaba adorando. Él nos ordenó derribar y destruir los ídolos y los Compañeros del Profeta lo hicieron también en cada país conquistado.

Tras ello, viene la destrucción de las piezas. El vídeo enlaza cada una de las destrucciones en una vorágine que parece no tener fin. Un cántico de fondo sigue recordando los mismos argumentos:

Destruir. Destruir. Destruir el estado de los Cruzados. Destruir los ídolos y las estatuas. Destruir las mentiras de los americanos. Los ídolos pertenecen al infierno. Estas estatuas e ídolos no existían en el tiempo de Muhammad y sus Compañeros, sino que los malvados adoradores [arqueólogos] las extrajeron de la tierra. (Smith et al., 2016, p. 177-178)

DAESH publicó este video el 6 de marzo de 2015 en las redes sociales. Recoge la destrucción de las piezas del museo de Mosul y con ello busca elaborar un discurso sobre el pasado que, aunque reconoce la existencia de Asirios y Acadios, tergiversa y reescribe la historia para poder figurar en ella como único protagonista y darnos su propia versión de los hechos.

La propaganda elaborada (materiales, vídeos o revistas como Dabiq, el magazine en inglés de DAESH, etc.) alude, como argumento para estas destrucciones, al rechazo de la idolatría (širk), es decir, de aquellas creencias, prácticas y evidencias materiales propias de pueblos o comunidades paganas, politeístas o adoradores de ídolos (așnam) que no cumplen con los preceptos ni la ortodoxia del islam: la adoración del único y verdadero dios cuya imagen no puede ser representada. Para ello se invocan pasajes muy concretos del Corán o sentencias de determinados juristas, conocidos por su radical visión de la ortodoxia islámica, como Ibn Taymiyya (m. 728/1328). Por ejemplo, el vídeo incluye citas del Corán (21:58) en las que se narra cómo Abraham destruyó varios ídolos. También se identifican las estatuas con imágenes del dios mesopotámico Nergal o se alude a la destrucción de ídolos por Muḥammad en la Kaaba tras entrar en La Meca para así justificar su destrucción. Esto, en 
cualquier caso, no es un argumento nuevo, sino que en el vídeo de al-Qaeda mostrando la demolición de los Budas de Bamiyán se recurría a otros versos coránicos (37:95) donde de nuevo Abraham destruía varios ídolos en defensa del monoteísmo (Erasing..., 2015; Harmanşhah, 2015; Shaw, 2015; Flood, 2016; Gruber, 2019) (Figura 3).

Figura 3 - Abraham destruye los ídolos de los Sabeos, Al-Biruni, al-Athar al-Baqiya (The Chronology of the Nations), Tabriz, Iran, 707/1307-8, Edinburg University Library, Ms. 161, folio 88v.

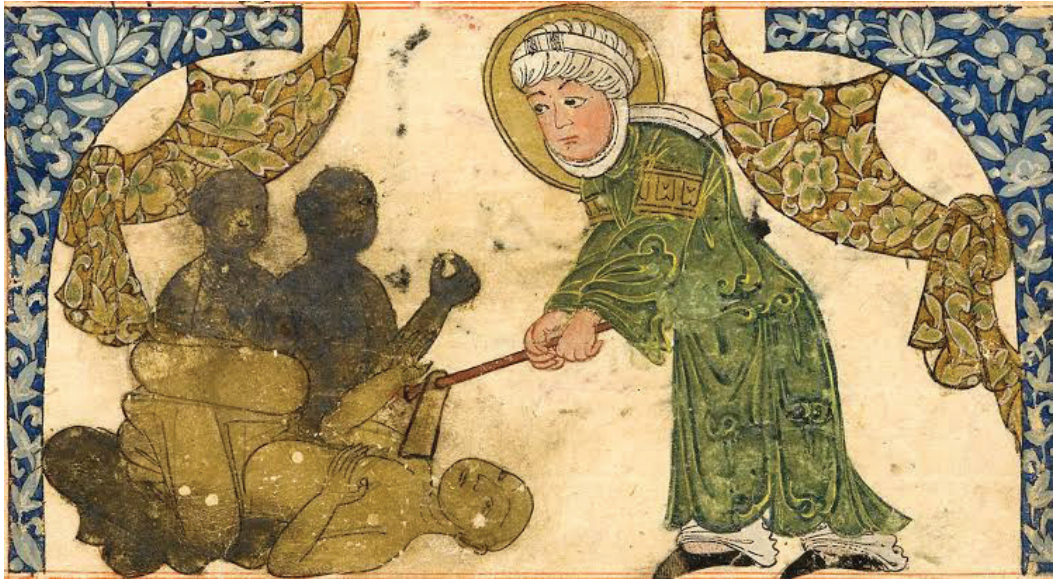

Los argumentos de DAESH para destruir estatuas y antigüedades aluden pues a aspectos religiosos, aunque en realidad esto no sea del todo cierto. Más bien hacen referencia a ciertos episodios y personajes de la tradición monoteísta e islámica como son Abraham y Muhammad, cuyas actuaciones toman como modelo y justificación. En realidad, el argumento esgrimido ahonda en la idea de $\hat{Y}$ āhiliyya o «época de la ignorancia» con el que se designa al periodo anterior a Muhammad, caracterizado por la ignorancia, la barbarie y la idolatría. Según DAESH todo lo perteneciente a la Ŷăhiliyya representa la antítesis del islam y debe ser por ello destruido. Con ello, se propone volver a los orígenes del islam y de sus primeras actuaciones, por lo que el discurso de los terroristas se nos presenta efectivamente como retrógrado, puritano y radical (Pines, 1990; Khalidi, 1994, p. 1-3; Drory, 1996; Abumalham, 2007).

El discurso de DAESH tiene, sin embargo, una característica adicional: tergiversa la historia. Varios ejemplos ponen en evidencia este aspecto. El concepto de $\hat{Y}$ āhiliyya hace referencia a un periodo, la época anterior a la venida 
de Muhammad, pero también a la actitud que lo caracterizaba, es decir, la «ignorancia» o, mejor dicho, el desconocimiento del mensaje divino. Lejos de tener la interpretación que plasma DAESH con sus martillos, Ŷăhiliyya es un concepto fundamental que recoge la ambigüedad y complejidad con la que las sociedades islámicas se acercan al pasado preislámico. En realidad, según ha evidenciado Peter Webb, en sus orígenes, el concepto no tendría connotaciones negativas, simplemente un sentido religioso y cronológico (Webb, 2014). Por ejemplo, Hišām b. al-Kalbī identificaba el periodo de la ŷāhiliyya con el universo religioso de las ciudades de Medina y La Meca previo a la irrupción del islam (Ibn al-Kalbī, 1914; traducción: Ibn al- Kalbī, 1952). Las connotaciones negativas vinculadas a la ŷăhiliyya aparecerían solo posteriormente, especialmente a partir del siglo XII y esta sería la interpretación que ofrecerían los primeros estudiosos europeos como el inglés Edward Gibbon, que asoció la $\hat{y} \bar{a}$ hiliyya con la ignorancia y barbarie que, a su entender, mostraban las comunidades locales hacia los vestigios de la antigüedad, justificando así la necesidad de rescatar (para la comunidad occidental) estas antigüedades del olvido y el rechazo y colonizar estos países (Gibbon, 1776-1789, v. 5, p. 234).

Curiosamente, DAESH no acude a la interpretación islámica primitiva del término ŷăhiliyya, sino que se apropia de la propia interpretación colonial de los occidentales, asumiendo que la única relación posible con la antigüedad que cabe a un musulmán es la ignorancia, el rechazo y la destrucción del pasado preislámico. Sin embargo, DAESH no se detiene aquí, sino que incluye dentro de lo rechazable o destruible no solo las antigüedades, sino todo aquello que no concuerda con su visión sunní, retrógrada y radical del islam. Eso explica los ataques y las demoliciones de templos y lugares de peregrinación musulmanes (chí́es y suníes), o que en abril de 2015 decidiera eliminar varias inscripciones coránicas grabadas o pintadas en las mezquitas de Mosul porque suponían un gasto de recursos y una frivolidad ornamental innecesaria (Flood, 2016, p. 119).

Otro aspecto tergiversado en el discurso de DAESH alude justamente a la destrucción de estatuas e imágenes figuradas, consideradas como ídolos y contrarias al derecho islámico, que establecería la prohibición de cualquier representación figurada. De este modo, el discurso de DAESH asume que el islam sería una religión iconoclasta, una idea también muy difundida y anclada en la sociedad occidental e incluso en los sectores académicos. Por ejemplo, K. A. C. Cresswell, uno de los mejores conocedores del arte y la arquitectura islámica, sostenía que "hay un rechazo temperamental e inherente en las razas semíticas al arte figurado" (Cresswell, 1946, p. 166). Recordaremos también la 
polémica desatada a raíz de la publicación de unas caricaturas de Muḥammad por un medio de comunicación danés y el debate suscitado entonces que tenía como centro precisamente esta idea de la prohibición islámica de la representación figurada (Klausen, 2009).

Esta caracterización de las comunidades orientales y musulmanas atiende de nuevo a un discurso colonialista. En realidad, el islam no debe ser considerada una religión iconoclasta, sino que el término correcto sería anicónica. La supuesta prohibición de la representación figurada (bi o tridimensional) no se basa en el Corán, sino en los hadices y tan solo estipula que no se pueden representar imágenes con alma (rūh) (Aḥmad Muhammad, 1955; Dodd, 1969; Barrucand, 1993; Baer, 1999; Brubaker, 2016; Flood, 2002; Flood, 2016; Gruber, 2019). La prohibición se refiere solo a la representación de dios y, efectivamente, la imagen figurada está ausente en los espacios religiosos (en las mezquitas encontramos decoración geométrica y vegetal), pero no así en los espacios profanos o seculares (Allen, 1988; Naef, 2007; Ali, 2015). Los ejemplos, antiguos y modernos, alusivos a una imagen (șurra) o una estatua (timtâal) en estos contextos son recurrentes a lo largo del mundo islámico y abarcan dibujo, pintura, escultura y medios digitales. Es solo así que se entiende la existencia de un museo como el Louvre Abu Dhabi, cuyo principal público han de ser esas poblaciones supuestamente incapaces de apreciar el arte, según afirmaba Cresswell.

En realidad, la tolerancia o rechazo del islam a la representación figurada (y a las estatuas antiguas) oscila según las regiones y los periodos a los que atendamos. Efectivamente, se encuentran momentos de destrucción, pero curiosamente, en la mayoría de los casos, las destrucciones se explican dentro de un contexto de crisis política, social o económica (Haarman, 1980, p. 62-65; Haarman, 1996, p. 612). No parece que quepa atribuir al islam más destrucciones que aquellas que pudieran achacarse al cristianismo, a otras religiones, $u$ a otros movimientos sociales o culturales. En el contexto en el que surge DAESH no encontramos efectivamente en un momento de gran inestabilidad en la región, en todos los sentidos. Es en este contexto en el que cabe entender el discurso de los terroristas, que, sin embargo, no tienen reparos en usar imágenes $\mathrm{y}$ videos para sus propios fines propagandísticos, lo que supone, a todas luces, una contradicción abierta con su propio ideario (Flood, 2016, p. 123-125). Curiosamente además, las citas coránicas sobre Abraham aducidas por los terroristas (21:58) equiparan las referencias a una imagen (șūra), o a imágenes $\mathrm{u}$ estatuas con parecido humano (tamațil pl. de timtāl), con los ídolos (așnam), 
cuando en realidad se trata de conceptos e ideas completamente distintas (Gruber, 2019, p. 14-15).

Las contradicciones y las tergiversaciones del pasado en el discurso de los terroristas no cesan aquí. Otros aspectos resultan igualmente relevantes e ilustran nuevamente acerca de la complejidad que se esconde detrás de este discurso. Por ejemplo, no es cierto que las piezas del museo procedieran de yacimientos descubiertos por europeos. En realidad, muchas de las ruinas eran visibles durante época medieval y fueron descritas con gran interés. Igualmente, muchas estatuas y piezas arqueológicas que hoy se atesoran en los museos occidentales formaban parte de la realidad de las comunidades locales, tenían nombres, convergían en ellas diversas historias y memorias, y en muchos casos se las consideraba talismanes protectores. Ahondaré en ello más adelante (Hamilakis, 2011; Bahrani, 2011; Anderson, 2015).

Asimismo, muchas de las piezas destruidas en Mosul no eran originales, sino copias de yeso, y, además, destruyeron las estatuas y grabaron el vídeo solo cuando ya habían expoliado el museo y habían sacado aquellas piezas que, por encargo o por demanda, les interesaba vender. De este modo, aunque sea únicamente por su valor económico, las antigüedades no son totalmente destruidas por DAESH. Este es el caso de una placa figurada en marfil procedente de Nimrud y expuesta en el museo, hallada en el botín localizado en la casa de Abū Sayyāf, líder del DAESH y encargado de las finanzas de la organización. La pieza fue descubierta en mayo de 2015, durante una campaña estadounidense dirigida contra Abū Sayyāf, junto con cientos de piezas expoliadas que daban cuenta por primera vez del tráfico de antigüedades que DAESH está llevando a cabo. Las cifras que reflejan las facturas que se encontraron en su casa muestran un volumen de negocio que, aun sin llegar a las cifras millonarias que algunos autores señalan, no deja de dar pingües beneficios (FBI, 2015; Erasing..., 2015; Taub, 2015).

Finalmente, la tergiversación del discurso de DAESH ahonda también en la idea de que nos encontramos ante un conflicto religioso, marcado por episodios y citas coránicas, sin embargo, estamos también equivocados si pensamos que las razones de los terroristas para destruir estatuas y antigüedades son solo o principalmente de tipo religioso. Como ya he señalado, estas actuaciones encierran más complejidad de la que pensamos y responden a circunstancias históricas muy concretas. Es el caso de la destrucción de los Budas de Bamiyán. Los talibanes no argumentaron que fueran ídolos religiosos, sino que esgrimieron su condición de iconos culturales. No podía haber una justificación teológica para dinamitarlos puesto que no había ya budistas en la región y, 
además, las imágenes habían sido mutiladas en el rostro con anterioridad y, por tanto, resultaban aceptables según la ortodoxia islámica. Era evidente que estaban inanimadas. El problema era que los colosales Budas eran un símbolo político e identitario y, como tal, eran un obstáculo para la construcción del discurso religioso y nacional de los talibanes en Afganistán (Flood, 2002, p. 655; Elias, 2007). Del mismo modo que los Budas de Bamiyán, muchas de las antigüedades y monumentos preislámicos en Siria e Iraq cuentan con fuertes connotaciones del pasado colonial y autocrático de la región.

\section{EL DISCURSO DE DAESH COMO REACCIÓN}

\section{AL DISCURSO COLONIAL Y NACIONALISTA}

Más allá de su apariencia como discurso religioso, DAESH busca responder la historia oficial, marcada por el pasado colonial y autocrático en la región. Por un lado, ciudades como Palmira han sido forjadas por y para occidentales desde el mismo momento en el que fueron "descubiertas" por los arqueólogos europeos (Schnapp, 1998; Larson, 1999-2000; Díaz-Andreu, 2007; Goode, 2009; Harloe, 2013). El Tetrapilón, destruido por DAESH en marzo de 2017, era en realidad una reconstrucción del siglo XX. Solo una columna era original. Por su parte, la población autóctona que vivía en la ciudad de Palmira desde época medieval fue desplazada en pro del turismo. Las imágenes de archivo nos recuerdan la existencia de un poblado beduino asentado en el templo de Bel, destruido ahora por DAESH. Los locales han quedado del todo olvidados, sus antigüedades expoliadas y trasladadas a los museos europeos y el discurso local sobre el pasado y su memoria desdeñado y minusvalorado por los investigadores hasta fechas recientes (Hamilakis, 2011; Anderson, 2015; Veyne, 2016; Baird; Kamash, 2019) (Figura 4).

Por otro lado, los regímenes autoritarios y dictatoriales de Siria e Iraq han recurrido también a este pasado para elaborar un discurso nacionalista e identitario de legitimación contra el que muchos se han rebelado. La identificación con los reyes mesopotámicos que Saddam Hussein trataba de promocionar, su reconstrucción de la antigua Babilonia como reflejo del esplendor de su mandato o el discurso nacional en Siria con respeto a determinados yacimientos y piezas son solo algunos ejemplos (Valter, 2002; Bernhardsson, 2005). Palmira, para muchos sirios, está asociada a las torturas y los encarcelamientos ordenados por Ḥāfiz al-'Assad (Haugbolle, 2008). Estos discursos continúan las dinámicas de época colonial y reflejan el fracaso del nacionalismo sirio e 
iraquí a la hora de vertebrar un discurso sobre el pasado que resulte integrador y verosímil para todos (Jones, 2018).

Figura 4 - La ciudad de Palmira (Tadmor en árabe) en Siria y las inmediaciones del templo de Bel ocupadas por la población local a principios del siglo XX. Imagen de dominio público procedente de la Matson Collection, Library of Congress.

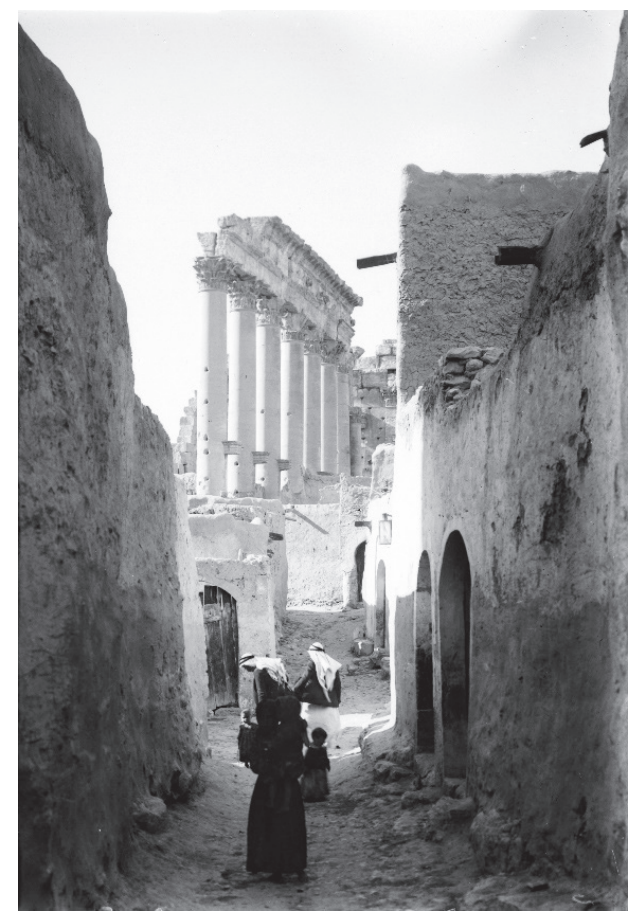

Los argumentos de DAESH se aprovechan de ello y su discurso busca responder y reescribir este pasado. Por ejemplo, en el número 8 de la revista Dabiq, consagrada a su propaganda, se indica:

Los kuffār [descreídos] habían desenterrado estas estatuas y ruinas en las últimas generaciones e intentaron retratarlas como parte de un patrimonio cultural y de una identidad de la que los musulmanes de Iraq debían enorgullecerse. Sin embargo, esto se opone al mensaje de Allāh y de su profeta y solo sirve a una agenda nacionalista que diluye la lealtad que se requiere de los musulmanes hacia su Señor. (Erasing..., 2015, p. 22) 
Y más adelante:

Los diversos regímenes de títeres y apóstatas establecidos por los cruzados después de la época colonial tienen versiones modificadas de la primera bandera diseñada por Mark Sykes [1879-1919], a veces utilizando tres de los cuatro colores originales. La bandera de la "Revuelta árabe" fue el padre de banderas que hoy representan a diferentes estados árabes nacionalistas... Estas banderas $\hat{y} a \bar{h} i l i ̄ ~[i g-$ norantes del mensaje divino] representan esencialmente a los cruzados, sus agentes apóstatas, el nacionalismo árabe y los títeres [regímenes] leales a los cruzados. (Erasing..., 2015, p. 22-23)

Los argumentos esgrimidos aquí por DAESH son casi enteramente de tipo político e histórico. Abarcan distintos niveles de referencia: el de la $\hat{Y} a \bar{h}$ iliyya, momento en el que se encuadran, como un todo, las referencias a Acadios o Asirios; el siglo VII, coincidiendo con la irrupción y expansión del islam; los siglos XI-XIII, aludiendo a la ocupación de los cruzados en el Próximo Oriente; y ya más recientemente, los siglos XIX y XX, correspondientes a la terrible huella del pasado colonial y autocrático de la región. En concreto, se señala el engaño urdido por los occidentales al desenterrar un pasado diferente y contrario al establecido por Muhammad, un pasado que sería ajeno a ellos, pero que los regímenes de Siria e Iraq habrían abrazado, en connivencia con los poderes occidentales, los descreídos y cruzados, como los definen, consiguiendo con ello apartarse del verdadero mensaje y centro de lealtad, el discurso del profeta.

DAESH señala por tanto que todo el pasado de la región es una recreación artificial, creada por políticos y arqueólogos occidentales, una idea que ya aparecía en el vídeo de la destrucción del museo de Mosul: "Estas estatuas e ídolos no existían en el tiempo de Muhammad y sus Compañeros, sino que los malvados adoradores [arqueólogos] las extrajeron de la tierra" (Smith et al., 2016, p. 177-178).

En realidad, no les falta parte de razón. Las fronteras establecidas en la arena del desierto fueron totalmente arbitrarias y respondían a los intereses de Gran Bretaña y Francia. La figura de Mark Sykes a la que alude el discurso de DAESH, no es otro que el delegado británico que, junto con Georges Picot, llegó a un acuerdo en 1916 para la repartición del ya extinto Imperio Otomano tras la Primera Guerra Mundial. De este modo, aparecen Jordania e Iraq, que adoptaron la forma de una monarquía, siguiendo el modelo británico, mientras 
que Siria, bajo control francés, adoptó la forma de república (Hourani; Khoury; Wilson, 2004; Barr, 2012; Cleveland; Bunton, 2016).

En lo que respecta al pasado de la región y sus ruinas, también se trata de un pasado "artificial” en muchos sentidos. Desde el siglos XVIII y XIX los arqueólogos occidentales excavaron distintos yacimientos: Mari, Ur, Assur, Nínive, Apamea, Persépolis o Palmira. Con ello los europeos destruyeron un pasado para recuperar otro. El caso de Palmira es un ejemplo paradigmático. Desmantelaron los edificios, las casas y la arquitectura de época otomana o mameluca para recuperar los monumentos y la ciudad greco-latina con la que se sentían identificados. La labor de descubrimiento conllevó pues una completa reescritura y reinvención del pasado de la región hasta formar las postales turísticas, no exenta de expolio, robo y destrucción en muchos casos. El ejemplo más triste de ello, y uno de los más recientes en el tiempo, es el saqueo e incendio del museo, la biblioteca y el archivo nacional de Iraq en Bagdad, ocurrido durante el protectorado estadounidense en 2003. Si uno ve las imágenes de los soldados destruyendo los adornos del palacio de Saddam Hussein comprobará también que no son muy diferentes de las imágenes actuales de los yihadistas de DAESH. Sin embargo, todo ello quedaba justificado bajo la égida de una mentalidad colonial que otorgaba a las comunidades locales el papel de meros espectadores, cuando no de ignorantes, incivilizados e incapaces de apreciar el valor de las antigüedades y de su propio bienestar (Córdoba Zoilo, 2004; Emberling; Hanson, 2008; Del Cerro Linares, 2011-2012; Espejel Arroyo, 2015).

Una imagen vale más que mil palabras. En este caso, se trata de la portada de la obra del inglés sir Austen Henry Layard, en la que daba cuenta de los descubrimientos realizados durante su excavación en Nínive, publicada en 1849. La imagen consiste en un dibujo de los trabajos que se habían llevado a cabo en la ciudad asiria, desenterrando una gigantesca escultura de unos lamassu, toros alados con cabeza de hombre, los mismos que ahora DAESH ha destruido en Nínive y en el museo de Mosul. Layard, en el centro, preside y dispone la organización de los trabajos, mientras que los locales siguen sus órdenes de manera obediente y disciplinada. En la parte de arriba, varias personas levantan los brazos en señal de incredulidad y espanto al comprobar lo que ha salido de la tierra (Layard, 1849, p. 2) (Figura 5).

El discurso de DAESH ahonda en esta arqueología colonial y artificial para justificar la destrucción de las piezas descubiertas, por ser fruto de su labor y ajenas al mensaje y el contexto de Muhammad. La referencia en el vídeo de las destrucciones en el museo de Mosul es directa (Figura 6). 
Figura 5 - Grabado de las excavaciones de sir Austen Henry Layard en Nínive y Nimrud y del hallazgo de los famosos lamassu, hoy en el Museo Británico en Londres. Tomado de Austen Henry Layard (1849), vol. 1, frontispicio.

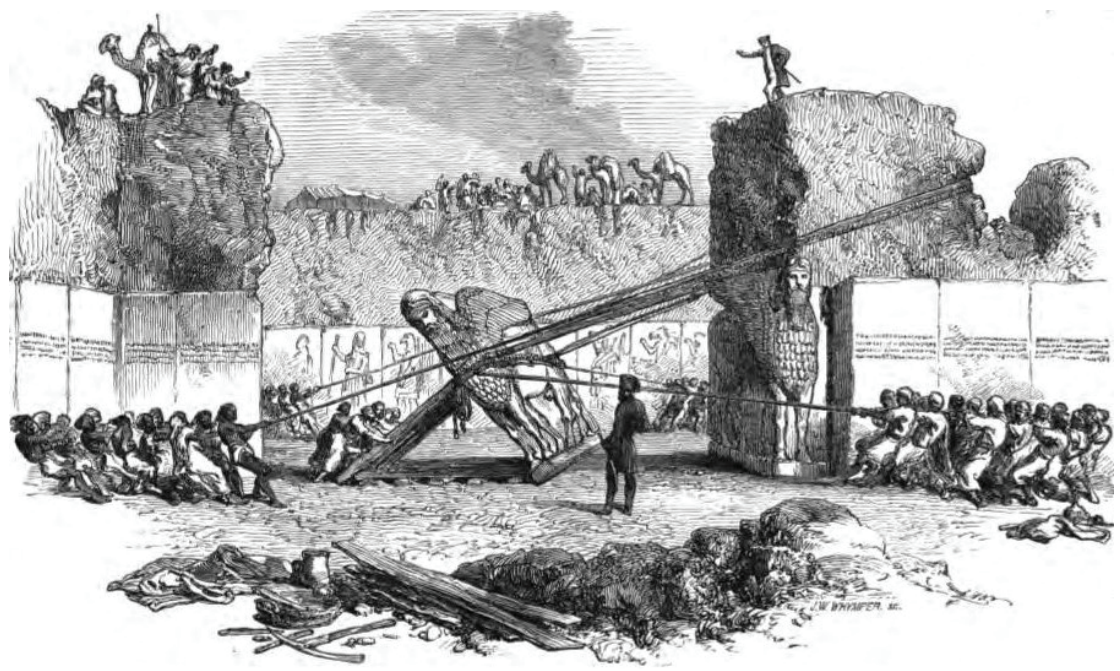

Figura 6 - Captura de pantalla de una escena del vídeo de DAESH sobre la destrucción de piezas en el Museo de Mosul.

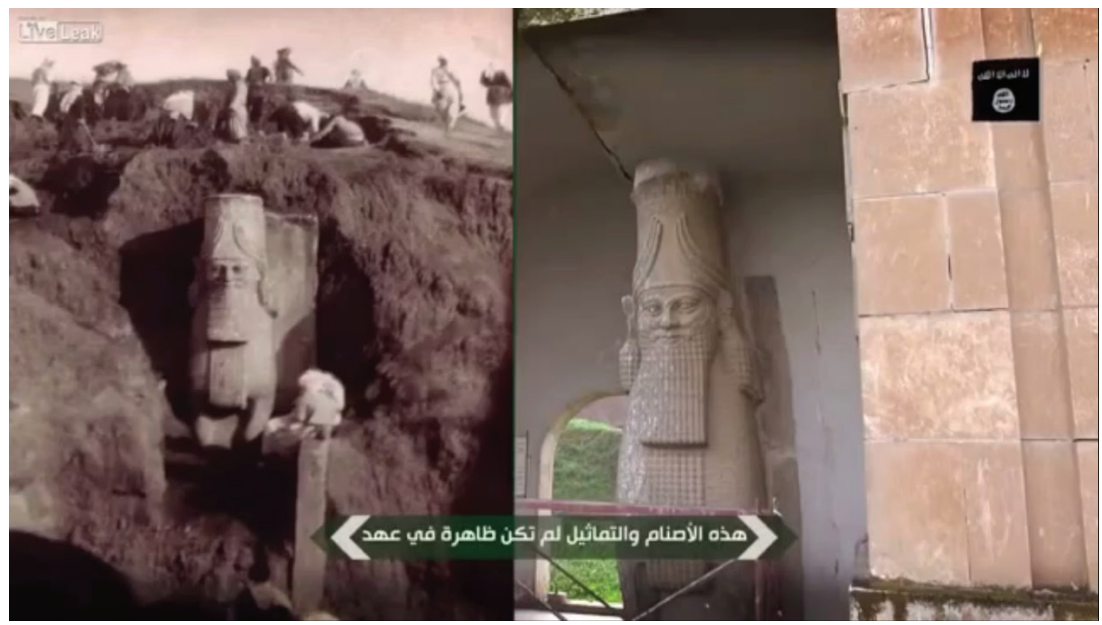




\section{EL DISCURSO OLVIDADO: OTRA FORMA DE VER LAS ANTIGÜEDADES}

Resulta pues evidente, atendiendo a lo visto hasta ahora, que las antigüedades y estatuas son "lugares de memoria", según la tradicional definición que hizo Pierre Nora, o "dispositivos" o "repositorios” de memorias, según los nuevos estudios sobre memoria cultural. Las antigüedades representan, para DAESH, un pasado colonial y nacionalista opuesto al mensaje de Muhammad, y para Occidente, los orígenes y valores de la civilización y el progreso, considerados como propios (Nora, 1989; Basu, 2012). Hoy en día esta visión sigue inalterada, no en vano, uno de los argumentos esgrimidos desde Francia para justificar la apertura del museo Louvre Abu Dhabi es el deseo de que éste contribuya a difundir ciertos valores en la región (Vicente, 2019). Ambas lecturas, sin embargo, son simplificadoras y unilaterales, con el añadido extra, en el caso de DAESH, de una voluntad destructiva. Ambas además ocultan otras formas de ver y entender estas antigüedades, algo que, en el caso de DAESH, resulta un objetivo esencial puesto que se pretende reescribir la historia para que figure en ella un mensaje unilateral del que únicamente ellos serían sus portadores. Sin embargo, quedan algunos vestigios de otro discurso en relación con las antigüedades, en el que estas formaban parte esencial de la vida, la identidad y las memorias de las comunidades locales.

Recientemente diversos estudios han puesto de manifiesto el papel desempeñado por los operarios, notables y arqueólogos locales en el "descubrimiento" de las ruinas antiguas excavadas por los arqueólogos europeos durante los siglos XVIII-XX. No se trata en ningún caso de un grupo pasivo o meramente curioso por los nuevos hallazgos, como quería hacernos creer H. Layard, ni se trataba de piezas desconocidas y ocultas bajo la tierra como afirma DAESH. En realidad, en muchos casos, estos personajes locales conocían muy bien dónde se encontraban estos vestigios puesto que habían convivido con ellos durante siglos. En torno a ellos circulaban diferentes memorias, nombres $\mathrm{y}$ tradiciones en forma de leyendas y relatos míticos. Incluso, como ya he señalado anteriormente, muchas de las estatuas y piezas de los museos occidentales formaban parte de la realidad material de estas comunidades, que habían reutilizado las piezas o emplazado estatuas en lugares concretos, atribuyéndoles poderes mágicos. Lejos de ser una realidad ajena y contraria al mensaje de Muhammad, estas estatuas y antigüedades habían convivido con la población local durante siglos y se habían integrado en la ortodoxia del islam y en el presente de las comunidades, no ya como ídolos de la $\hat{Y} a \overline{h i l i y y a}$, sino como talismanes y repositorios de sus propias memorias e identidades. 
Los ejemplos que se pueden aducir son varios. Zainab Bahrani y Zeyneb Çelik han mostrado esta otra realidad. Arqueólogos locales como Osman Hamdi Bey (1842-1910) o Hormuzd Rassam (1826-1910) rivalizaban con los europeos en la excavación de yacimientos y a menudo compartían campamento y sufrían, como los peones, los desmanes e ilegalidades de los arqueólogos europeos (Bahrani, 2011; Çelik, 2016, p. 135-173). Igualmente son conocidas las referencias de época medieval y moderna a yacimientos, ruinas y estatuas antiguas en las ciudades de Mesopotamia y Próximo Oriente. Caroline Janssen ha estudiado el caso de la antigua Babilonia, cuya proyección en el imaginario local estaba asociada a míticas figuras de la tradición bíblica y coránica (Janssen, 1995); y Roy Mottahedeh y Sarah Bowen-Savant han hecho lo propio para el mundo iranio o persa (Mottahedeh, 1994; Mottahedeh, 2013; Bowen-Savant, 2013). Monumentos antiguos en las ciudades sirias de Palmira o Baalbek habrían sido construidos por Salomón, quién según el Corán, controlaba diversos genios que habrían construido para él algunas de las maravillas de la antigüedad (Rubiera Mata, 1981, p. 45-54; Mottahedeh, 2013; Bowen-Savant, 2013, p. 54-59).

Concretamente, en Palmira, sabemos que algunos de los monumentos antiguos, como el templo de Bel, fueron reocupados, convertidos en fortalezas. Se fundó también una mezquita. La ciudad estuvo ocupada de manera importante hasta mediados del siglo VIII, cuando tuvo lugar un terrible terremoto en la región. A partir de entonces su protagonismo decayó sensiblemente en los siglos posteriores, viéndose afectada también por los conflictos que tuvieron lugar entre los siglos XIII-XIV (Genequand, 2008; Baird; Kamash, 2019).

Las noticias árabes, sin embargo, continúan aludiendo a la ciudad, destacando sus monumentos antiguos. De este modo, algunos autores árabes aluden al hallazgo de una estatua. Las noticias son tardías, pero aluden a un contexto propio del siglo VIII. Según se indica, Marwān, el último califa omeya, destruyó la muralla de Palmira así como una estatua femenina que había sido hallada junto con una inscripción que indicaba cuál era su nombre, Palmira. La inscripción advertía de terribles consecuencias contra aquél que atentara contra la estatua. Desoyendo la advertencia, Marwān ordenó quemarla. Días después, según se afirma, el califa omeya fue derrotado por los 'abbāsíes y ello significó el fin de su dinastía (Al-Qazwīnī, 1848-1849, p. 169-170; Rubiera Mata, 1981, p. 53). La noticia, como resulta evidente, contiene una serie de elementos o topoi que resultan comunes a otras historias (la estatua que porta un mensaje de advertencia, que es desoído, acarreando entonces diversas consecuencias). No por ello la noticia debe rechazarse de plano, sino que cabe destacar diversos 
detalles, particularmente, la noticia de un hallazgo de una estatua, algo que en principio sí resulta verosímil, y la consideración de la estatua como un elemento capaz de integrar tanto el nombre como el pasado de la ciudad, dotada de poderes mágicos y talismánicos, de tal manera que el daño sufrido por la ciudad y la estatua acaban revirtiendo en el causante. Por último, la noticia sirve para explicar, seguramente a posteriori, sucesos históricos destacados cuyo esclarecimiento resulta desconocido, controvertido o formaría parte de los designios divinos. En este caso, la noticia de la destrucción de la estatua de Palmira debe encuadrarse en el contexto del terremoto sufrido por la región y el cambio político y dinástico que tuvo lugar a mediados del siglo VIII.

A la vista de estas noticias resulta más que evidente que la población local conocía e interactuaba con estas estatuas y vestigios de la antigüedad. Esto es algo que el discurso de DAESH silencia completamente, puesto que evidencia una relación con la antigüedad en la que ésta constituía una referencia fundamental dentro del relato cultural e identitario de las comunidades locales. La antigüedad resulta aquí un elemento flexible y multifacético, capaz de adoptar diferentes formas, funciones y explicaciones, un elemento central para articular las narraciones acerca del pasado, el presente y el futuro de cada comunidad. En definitiva, una visión mucho más compleja y diversa que la simple catalogación de estas estatuas como ídolos de la Ŷăhiliyya, según postula el relato de los terroristas. DAESH, en cambio, ahonda en ese discurso de alienación el pasado, subrayando que este es ajeno y extraño a los locales.

Esta era la realidad de muchos de los vestigios y yacimientos de Mesopotamia y Próximo Oriente durante la Edad Media y los siglos posteriores. La irrupción del colonialismo y la arqueología occidental provocó un cambio sensible, quizás no tanto en la forma en la que estas antigüedades eran vistas y consideradas por las comunidades locales, pero desde luego sí por parte de los poderes estatales, que utilizaron el pasado para construir nuevos relatos históricos de corte nacionalista, impulsados o influenciados por los propios modelos narrativos que las potencias occidentales estaban desarrollando en el siglo XIX (Eldem, 2011). De este modo, primero el Imperio Otomano, y posteriormente, cada uno de los nuevos países surgidos tras la Primera Guerra Mundial (Siria, Líbano, Jordania, Iraq) elaboraron un discurso propio que rechazó por completo esta otra forma de ver las antigüedades, más apegada a las tradiciones mágicas, populares y culturales de las comunidades de Oriente (Valter, 2002; Bernhardsson, 2005; Çélik, 2016).

Esta otra percepción del pasado y sus vestigios, más compleja y diversa, como ya he señalado, lejos de desaparecer, parece haber continuado, pese a 
todo ello, hasta hoy en día. A un nivel más internacional cabe destacar un grupo de mujeres refugiadas sirias de la guerra, participando en una adaptación de la obra de Eurípides, Las Troyanas. Su versión, Las reinas de Siria, es un éxito teatral y también un documental que sirve para denunciar las atrocidades de esta guerra y reivindicar el papel de las mujeres (https://www.trojanwomenproject.org). En un ámbito más local, el de las comunidades locales sometidas a DAESH, es menos halagüeño si cabe. Los vídeos de los terroristas tienen aquí su versión más terrible puesto que el Diwān al-Rikaz (Ministerio de recursos o tesoros subterráneos de DAESH), que también controla los pozos petrolíferos, es el encargado de orquestar un sistema que incentiva a la población local a destruir su propio pasado como única salida para la supervivencia, ofreciendo el pago en monedas de un porcentaje del valor (entre el 20 y el 50 por 100) de cada pieza u objeto encontrado, que posteriormente acabará en el mercado negro y en las vitrinas de algún coleccionista privado, muchos de ellos, jeques árabes del Golfo Pérsico (Al-Azm, 2014; Brodie; Sabrine, 2018). ${ }^{3}$

\section{CONSIDERACIONES FINALES}

Las antigüedades, y en concreto las estatuas, se encuentran en el centro de debates y conflictos actuales en torno a determinadas narrativas históricas que derivan directamente del pasado colonial y autocrático en el Próximo Oriente. El discurso de DAESH, esencialmente radical, retrógrado y destructivo, esconde, sin embargo, una complejidad mayor. Se asienta en el pasado de ciudades como Palmira o Mosul y cuestiona el discurso oficial esgrimido desde Occidente o desde los propios gobiernos locales. Se camufla como un discurso religioso, invocando episodios y personajes religiosos, apuntando que las estatuas antiguas son ídolos (așnam) de la Ŷăhiliyya, el pasado anterior al islam, sin embargo, en realidad, los argumentos empelados atienden al contexto político y cultural de la región, tergiversan la historia antigua, medieval y contemporánea, ocultan el tráfico de antigüedades con el que se financian, y se apropian de ideas esgrimidas durante el colonialismo europeo, definiendo el islam como una religión iconoclasta y destructora de todo lo que le precede.

Ante todo, DAESH busca ocultar una historia alternativa en la que estas estatuas y vestigios de la antigüedad, lejos de ser elementos extraños y ajenos a las comunidades locales del Próximo Oriente, constituían elementos centrales en la construcción de la identidad y memoria local. Las estatuas tenían nombres, cumplían una función en la sociedad, y estaban plenamente integradas en la realidad y en la ortodoxia islámica, como talismanes y estatuas 
protectoras. Con esta idea continúan una tradición occidental que ve en las estatuas y antigüedades objetos de arte e historia cuyo máximo valor reside en la transmisión de valores e ideas de civilización y progreso con los que Occidente se identifica. DAESH retoma este discurso de alienación de las comunidades locales a su propio pasado, reinventando la antigüedad como la antítesis del islam.

Las antigüedades, y concretamente las estatuas, por su condición de representar la figura humana y a gobernantes y dioses pasados, son reliquias y testimonios de un determinado pasado, sin embargo, este pasado también puede ser alterado, y con ellos, las estatuas son reinterpretadas, para transmitir un nuevo discurso. Las estatuas son dispositivos o repositorios que albergan y recrean la antigüedad. De este modo, sobre la historia de la que las estatuas son evidencia y prueba, Occidente reescribió y reinventó en buena medida la antigüedad, como espejo de su propio pasado y futuro, y ahora, DAESH busca reescribir sobre la piedra, a base de martillazos, un nuevo discurso, que hace de ellas, simples ídolos.

\section{REFERENCIAS}

ABUMALHAM, Montserrat. De la ignorancia al conocimiento y la sumisión: de la yahiliyya al islam. Bandue -Revista de la Sociedad Española de Ciencias de las Religiones, v. 1, p. 7-18, 2007.

AHMMAD MUḤAMMAD, Isa. Muslims and taswir. The Muslim World, v. XLV, n. 3, p. 250-268, 1955.

AL-AZM, Amr. ISIS’ Antiquities Sidelines. New York Times, 2 Sept. 2014. Disponible en: www.nytimes.com/2014/09/03/opinion/isis-antiquities-sideline.html. Acceso el: 10 dic. 2019.

AL-QAZWĪNİ. Ātâ̄r al-bilad. Texto árabe editado por Ferdinand Wüstenfeld. Gottingen: Johann Wolfgang Goethe-Universität Frankfurt, 1848-1849.

ALI, Nadia. The royal veil: early Islamic figural art and the Bilderverbot reconsidered. Religion, v. XLVII, n. 3, p. 425-444, 2015.

ALLEN, Terry. Aniconism and Figural Representation in Islamic Art, en Terry Allen. In: ALLEN, Terry. Five Essays on Islamic Art. Sebastopol, CA: Solipsist Press, 1988. p. 17-37.

ANDERSON, Benjamin. "An alternative discourse": local interpreters of antiquities in the Ottoman Empire. Journal of Field Archaeology, v. XL, n. 4, p. 450-460, 2015.

ANDERSON, Benjamin; ROJAS, Felipe. Antiquarianisms: Contact, Conflict, Comparison. Oxford: Oxford University Press, 2017. 
LAS AUTORIDADES detienen e interrogan durante más de dos días a dos periodistas suizos. Reporteros sin Fronteras, 14 Nov. 2017. Disponible en: https://www.rsf-es. org/news/emiratos-arabes-unidos-las-autoridades-detienen-e-interrogan-durante-mas-de-dos-dias-a-dos-periodistas-suizos/. Acceso el: 15 dic. 2019.

BAER, Eva. The Human Figure in Early Islamic Art: Some Preliminary Remarks. Muqarnas, v. 16, p. 32-41, 1999.

BAHRANI, Zainab. Interview. 2015. Disponible en: www.artnews.com/2015/11/11/ this-is-a-genocide-art-historian-zainab-bahranion-isiss-destruction-of-cultural-heritage. Acceso el: 15 dic. 2017.

BAHRANI, Zainab. Untold Tales of Mesopotamian Discovery. In: BAHRANI, Zainab; ÇELIK, Zeynep; ELDEM, Edhem (ed.). Scramble for the Past: A Story of Archaeology in the Ottoman Empire, 1753-1914. Istanbul: Salt, 2011. p. 125-155.

BAIRD, Jennifer; KAMASH, Zena. Remembering Roman Syria: Valuing Tadmor-Palmyra, from "Discovery" to Destruction. Bulletin of the Institute of Classical Studies, v. LXII, n. 1, p. 1-29, 2019.

BARR, James. A Line in the Sand: Britain, France and the Struggle That Shaped the Middle East. New York: Simon \& Schuster, 2012.

BARRUCAND, Marianne. Les fonctions de l'image dans la société islamique du Moyen-Âge. Annuaire de l'Afrique du Nord, v. 22, p. 59-67, 1993.

BASU, Laura. Ned Kelly as Memory Dispositif: Media, Time, Power, and the Development of Australian Identities. Berlin: De Gruyter, 2012.

BEARDEN, Lauren. Complex Destruction: Near Eastern Antiquities and the ISIS Spectacle. 2016. Tesis (PhD) - Georgia State University. Atlanta, 2016. Disponible en: https://scholarworks.gsu.edu/art_design_theses/205/. Acceso el: 20 dic. 2017.

BERNHARDSSON, Magnus. Reclaiming a Plundered Past: Archaeology and Nation Building in Modern Iraq. Austin, TX: University of Texas Press, 2005.

BOWEN-SAVANT, Sarah. The New Muslims of Post-Conquest Iran: Tradition, Memory, and Conversion. Cambridge: Cambridge University Press, 2013.

BRODIE, Neil; SABRINE, Isber. The Illegal Excavation and Trade of Syrian Cultural Objects: A View from the Ground. Journal of Field Archaeology, v. 43, p. 74-84, 2018.

BRUBAKER, Leslie. Making and Breaking: Images and Meaning in Byzantium and Early Islam. In: BOLDRICK, Stacy et al. Striking Images, Iconoclasms Past and Present. Burlington, VT: Routledge, 2016. p. 14-24.

ÇELIK, Zeyneb. About Antiquities: Politics of Archaeology in the Ottoman Empire. Dallas, TX: Dallas University Press, 2016.

CLEVELAND, William L.; BUNTON, Martin. A History of the Modern Middle East [1994]. London: Avalon, 2016.

CÓRDOBA ZOILO, Joaquín. Iraq: memoria y expolio. Robo y comercio ilegal de antigüedades 1991-2003. Nación Árabe, v. 51, p. 11-21, 2004. 
Jorge Elices Ocón

CRESSWELL, Keppel A. C. The lawfulness of Painting in Islam. Ars Islamica, v. 11-12, p. 165-166, 1946.

DEL CERRO LINARES, Carmen. El patrimonio arqueológico e histórico iraquí y su destrucción desde la Guerra del Golfo hasta nuestros días. Isimu, v. 14-15, p. 81101, 2011-2012.

DÍAZ-ANDREU, Margarita. A World History of Nineteenth-Century Archaeology. Oxford: Oxford University Press, 2015.

DODD, Erica C. The Image of the Word: Notes on the Religious Iconography of Islam. Berytus - Archaeological Studies, v. 18, p. 35-79, 1969.

DRORY, Rina. The Abbasid Construction of the Jahiliyya: Cultural Authority in the Making. Studia Islamica, v. 83, p. 33-49, 1996.

EICHSTAEDT, Peter. Above the Din of War: Afghans Speak About Their Lives, Their Country, and Their Future-and Why America Should Listen, Chicago, IL: Chicago Review Press, 2013.

ELDEM, Edhem. From Blissful Indifference to Anguished Concern: The Transformation of Ottoman Perceptions of Antiquities, 1799-1869. In: BAHRANI, Zainab; ÇELIK, Zeynep; ELDEM, Edhem (ed.). Scramble for the Past: A Story of Archaeology in the Ottoman Empire, 1753-1914. Istanbul: Salt, 2011. p. 281-329.

ELIAS, Jamal J. (Un) Making Idolatry: From Mecca to Bamiyan. Future Anterior Journal of Historic Preservaton, History, Theory, and Criticism, v. 4, p. 12-29, 2007. EMBERLING, Geoff; HANSON, Katharyn (ed.). Catastrophe! The looting and destruction of Iraq's past. Chicago, IL: Oriental Museum Prublication Press, 2008.

ERASING the Legacy of a Ruined Nation. Dabiq, v. 8 (Jumada al-Akhirah 1436/marzo 2015), p. 22-24, 2015.

ESPEJEL ARROYO, Fernando. El patrimonio arqueológico iraquí y su destrucción a lo largo del tiempo. Panta Rei, p. 9-25, 2015.

FBI. ISIL and Antiquities Trafficking. 26 ago. 2015. Disponible en: www.fbi.gov/news/ stories/isil-and-antiquities-trafficking. Acceso el: 12 mayo 2017.

FLOOD, Finbarr Barry. Between Cult and Culture: Bamiyan, Islamic Iconoclasm, and the Museum. The Art Bulletin, v. 84, n. 4, p. 641-659, 2002.

FLOOD, Finbarr Barry. Idol Breaking as Image Making in the "Islamic State". Religion and Society - Advances in Research, v. 7, p. 116-138, 2016.

GAMBONI, Dario. The Destruction of Art: Iconoclasm and Vandalism since the French Revolution. London: Reaktion Books, 1997.

GIBBON, Edward. The History of the Decline and Fall of the Roman Empire. London: [s. n.], 1776-1789.

GOODE, John Fitzgerald. Negotiating for the Past: Archaeology, Nationalism, and Diplomacy in the Middle East, 1919-1941. Austin, TX: Austin University Press, 2009. 
GRUBER, Christiane, Idols and Figural Images in Islam: A Brief Dive into a Perennial Debate. In: GRUBER, Christiane (ed.). The Image Debate: Figural Representation in Islam and Across the World. London: Gingko Press, 2019. p. 9-29.

HAARMAN, Ulrich. Medieval Muslim Perceptions of Pharaonic Egypt. In: LOPRIENO, Antonio (ed.). Ancient Egyptian Literature: History and Forms, Leiden: Brill, 1996. p. 605-627.

HAARMAN, Ulrich. Regional Sentiment in Medieval Islamic Egypt. Bulletin of the School of Oriental and African Studies, v. XLIII, n. 1, p. 55-66, 1980.

HAMILAKIS, Yannis. Indigenous Archaeologies in Ottoman Greece. In: BAHRANI, Zainab; ÇELIK, Zeynep; ELDEM, Edhem (ed.). Scramble for the Past: A Story of Archaeology in the Ottoman Empire, 1753-1914. Istanbul: Salt, 2011. p. 49-69.

HARLOE, Katherine. Winckelmann and the Invention of Antiquity: History and Aesthetics in the Age of Altertumswissenschaft. Oxford: Oxford University Press, 2013. HARMANŞHAH, Ömür. ISIS, Heritage, and the Spectacles of Destruction in the Global Media. Near Eastern Archaeology, v. 78, n. 3, p. 170-177, 2015.

HAUGBOLLE, Sune. Imprisonment, Truth Telling, and Historical Memory in Syria. Mediterranean Politics, v. 13, p. 261-276, 2008.

HOURANI, Albert; KHOURY, Philip S.; WILSON, Mary Ch. The Modern Middle East: A Reader. [1993]. Berkeley, CA: Berkeley University Press, 2004.

IBN AL-KALBİ. The Book of Idols or The Kitāb al-Așnām. Traducción al inglés de Nabih A. Faris. Princeton, NJ: Princeton University Press, 1952.

IBN AL-KALBĪ. Kitāb al-aṣnām. Texto árabe editado por Ahmad Z. Zakī. El Cairo: al-Mațba'ah al-Amīrīyah, 1914.

JANSSEN, Caroline. Bābil, the City of Witchcraft and Wine: The Name and Fame of Babylon in Medieval Arabic Geographical Texts. Ghent: University of Ghent Press, 1995.

JONES, Christopher W. Understanding ISIS's destruction of antiquities as a rejection of nationalism. Journal of Eastern Mediterranean Archaeology and Heritage Studies, v. 6, p. 31-58, 2018.

KHALIDI, Tarif. Arabic Historical Thought in the Classical Period. Cambridge: Cambridge University Press, 1994.

KLAUSEN, Jytte. The Cartoons That Shook the World. New Haven, CT: Yale University Press, 2009.

KOLRUD, Kristine; PRUSAC, Marina. Iconoclasm from Antiquity to Modernity. Burlington, VT: Ashgate, 2014.

KRISTENSEN, Troels M.; STIRLING, Lea. The Afterlife of Greek and Roman Sculpture: Late Antique Responses and Practices, East Lansing, MI: Michigan State University Press, 2016. 
LARSON, Victoria T. Classics and the Acquisition and Validation of Power in Britain's "Imperial Century" (1815-1914). International Journal of the Classical Tradition, v. 6, p. 185-225, 1999-2000.

LAYARD, Austen Henry. Nineveh and its remains. London: [s. n.], 1849.

LEROY, Aliaume. Smuggled Antiquities Fund ISIL's Campaigns. Dec. 6, 2014. Disponible en: www.bellingcat.com/news/mena/2014/12/06/smuggled-antiquities-fund-isilscampaigns. Acceso el: 17 oct. 2017.

MARCHAND, Suzanne L. Down from Olympus: Archaeology and Philhellenism in Gernany, 1750-1970. Princeton, NJ: Princeton University Press, 1996.

MORGAN, Llewelyn. The Buddhas of Bamiyan. Cambridge, MA: Harvard University Press, 2012.

MOTTAHEDEH, Roy. The Eastern Travels of Solomon: Reimagining Persepolis and the Iranian Past. In: COOK, M. et al. (ed.). Law and Tradition in Classical Islamic Thought: Studies in Honor of Professor Hossein Modarressi. New York, 2013. p. 247-267.

MOTTAHEDEH, Roy. Some Islamic Views of the Pre-Islamic Past. Harvard Middle Eastern and Islamic Review, v. 1, n. 1, p. 17-26, 1994.

NAEF, Silvia. Las artes en el Islam: entre prohibición y figuración. Boletín Hispánico Helvético, v. 9, p. 125-138, 2007.

NORA, Pierre. Between Memory and History: Les lieux de mémoire. Representation, v. 26, n. especial, Memory and Counter Memory, p. 7-24, 1989.

PINES, Shlomo. Jahiliyya and 'Ilm. Jerusalem Studies in Arabic and Islam, v. 13, p. 175-194, 1990.

RUBIERA MATA, Maria J. La arquitectura en la literatura árabe. Madrid: Sílex, 1981. SCHNAPP, Alain. La conquête du passé: aux origines de l'archéologie. Paris: LGF, 1998. SCHNAPP, Alain. Vers une histoire universelle des antiquaire. Perspective - la revue de l'INHA: actualités de la recherche en histoire de l'art, v. 1, p. 10-18, 2008.

SCHNAPP, Alain. Vestigios, monumentos y ruinas: Oriente frente a Occidente. In: EL GABINETE de Maravillas. Cuadernos de la Fundación M. Botín. Santander: Observatorio de Analisis de tendencias, 2007. p. 21-52.

SCHNAPP, Alain et al. World Antiquarianism: comparative perspectives. Los Angeles, CA: The Getty Research Institute, 2013.

SEISDEDOS, Iker. El Louvre Abu Dabi ve la luz en el desierto. El País, 8 nov. 2017. Disponible en: https://elpais.com/cultura/2017/11/07/actualidad/1510062694_ 797904.html Acceso el: 12 dic. 2019.

SHAW, Wendi M. K. Destroy Your Idols. X- Tra Contemporary Art Quarterly, v. 18, n. 1, p. 73-94, 2015.

SHAW, Wendy M. K. Possessors and Possessed: Museums, Archaeology, and the Visualization of History in the Late Ottoman Empire. Berkeley, CA: Berkeley University Press, 2003. 
SMITH, Claire et al. The Islamic State's Symbolic War: Daesh's Socially Mediated Terrorism as a Threat to Cultural Heritage. Journal of Social Archaelogy, v. 16, n. 2, p. 164-188, 2016.

TAUB, Ben. The Real Value of the ISIS Antiquities Trade. Dec. 4, 2015. Disponible en: www.newyorker.com/news/news-desk/the-real-value-of-the-isis-antiquities-trade. Acceso el: 15 dic. 2017.

VALTER, Stéphane. La construction nationale syrienne: légitimation de la nature communautaire du pouvoir par le discours historique. Paris: CNRS, 2002.

VICENTE, Alex. ¿Qué busca Francia al exportar sus museos? El País, 14 dic. 2019. Disponible en: https://elpais.com/elpais/2019/12/13/ideas/1576241625_837560. html?ssm=FB_CC\&fbclid=IwAR1szADgJ_AjJqY15cyTfTdAnJ38s d646yGWgYF27hQ8oD2iRImIRHIS3f8. Acceso el: 14 dic. 2019.

WEBB, Peter. Creating Arab Origins: Muslim Constructions of al-Jāhiliyya and Arab History. 2014. Tesis (PhD) - University of London. London, 2014. Disponible en: http://eprints.soas.ac.uk/18551/1/Webb_3618.pdf. Acceso el: 15 dic. 2015.

\section{NOTAS}

${ }^{1}$ Este artículo ha sido desarrollado gracias a una beca concedida por Fapesp, 2018/15102-7.

${ }^{2}$ DAESH es la transliteración del acrónimo árabe "Estado Islámico de Irak y Levante", pero dependiendo de cómo se conjugue puede significar también "algo que aplastar o pisotear", "intolerante" o "el que siembra la discordia". DAESH ha sido utilizado por algunas organizaciones gubernamentales para evitar la legitimación política que buscan con este nombre. Por eso, siempre me referiré a ellos como DAESH.

${ }^{3}$ Esta práctica de obligar a la población local a actuar en contra de su propio pasado y destruirlo se documenta también en el caso de los Budas de Bamiyán (EICHSTAEDT, 2013, p. 203-207).

Artículo recibido el 29 de enero de 2020. Aprobado el 25 de mayo de 2020. 